THE UNIVERSITY OF MISSOURI ENGINEERING REPRINT SERIES

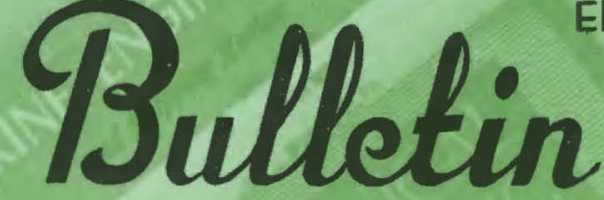

Reprint Number 15

Engineering Experiment Station

Columbia, Missouri

\title{
LIGHTWEIGHT AGGREGATES \\ FOR STRUCTURAL CONCRETE
}

\section{ADRIAN PAUW}

Associate Professor of Civil Engineering

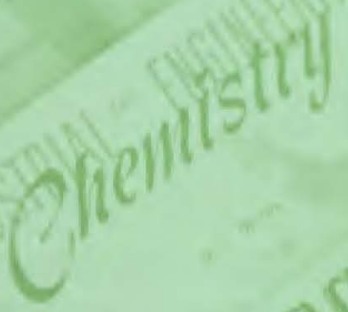

Reprinted from the Proceedings of the AMERICAN SOCIETY OF CIVIL ENGINEERING, Vol. 8I, January 1955 


\section{COLLEGE OF ENGINEERING THE ENGINEERING EXPERIMENT STATION}

The Engineering Experiment Station was organized in 1909 as a part of the College of Engineering. The staff of the Station includes all members of the Faculty of the College of Engineering, together with Research Assistants supported by the Station Funds.

The Station is primarily an engineering research institution engaged in the investigation of fundamental engineering problems of general interest, in the improvement of engineering design, and in the development of new industrial processes.

The Station desires particularly to co-operaie with industries of Missouri in the solution of such problems. For this purpose, there is available not only the special equipment belonging to the Station but all of the equipment and facilities of the College of Engineering not in immediate use for class instruction.

Inquiries regarding these matters should be addressed to

The Director,

Engineering Experiment Station

University of Missouri

Columbia, Missouri

\section{THE UNIVERSITY OF MISSOURI BULLETIN}

Publiahed by the Univeraity of Missouri at Room 102, Building T-3, Columbia, Missouri. Entered as second-class matter, January 2, 1914 , at poat office st Columbia, Miesouri, under Act of Congress of August 24, 1912. Iseued four times monthly Ootober through May, three times monthly June through September. 

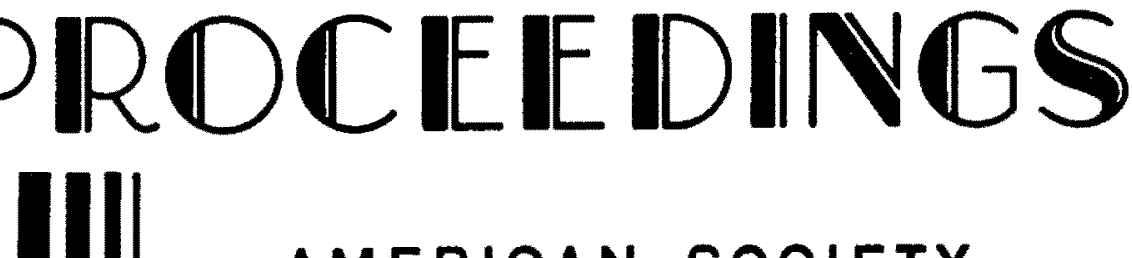

\section{AMERICAN SOCIETY of \\ CIVIL ENGINEERS}

JANUARY, 1955

_LIGHTWEIGHT AGGREGATES FOR

STRUCTURAL CONCRETE

by Adrian Pauw, A.M. ASCE

\section{STRUCTURAL DIVISION}

(Discussion open until May 1, 1955)

Copyright 1955 by the Amkrican SOCETY OF CNH. ENGineres Printed in the Uniled States of America

Headquarters of the Society $33 \mathrm{~W}$. 39th St.

New York 18, N. Y.

PRICE \$0.50 PER COPY 


\section{THIS PAPER}

--represents an effort by the Society to deliver technical data direct from the author to the reader with the greatest possible speed. To this end, it has had none of the usual editing required in more formal publication procedures.

Readers are invited to submit discussion applying to current papers. For this paper the final date on which a discussion should reach the Manager of Technical Publications appears on the front cover.

Those who are planning papers or discussions for "Proceedings" will expedite Division and Committee action measurably by first studying "Publication Procedure for Technical Papers" (Proceedings - Separate No. 290). For free copies of this Separate-describing style, content, and format-address the Manager, Technical Publications, ASCE.

Reprints from this publication may be made on condition that the full title of paper, name of author, page reference, and date of publication by the Society are given.

The Society is not responsible for any statement made or opinion expressed in its publications.

This paper was published at $1745 \mathrm{~S}$. State Street, Ann Arbor, Mich., by the American Society of Civil Engineers. Editorial and General Offices are at 33 West Thirty-ninth Street, New York 18, N. Y. 


\title{
LIGHTWEIGHT AGGREGATES FOR STRUCTURAL CONCRETE
}

\author{
Adrian Pauw, ${ }^{1}$ A.M. ASCE
}

\section{INTRODUCTION}

In recent years interest in lightweight concrete has become widespread, not only on account of its light weight, which is desirable in floor slabs, walls and partitions, but also because of its high thermal and sound insulation properties. Lightweight concretes may be produced by the following methods:

1) Formation of air voids in cement paste. Such voids may be produced either by the addition of some substance to the cement causing it to foam, or by mixing a cement slurry with a preformed foam.

2) Formation of air voids in the concrete by omitting the fine aggregates.

3) The use of lightweight aggregates which owe their low density to the presence of enclosed voids in the aggregate.

Combinations of the above methods may also be employed in producing lightweight concrete.

To date the production of lightweight concrete in this country has been limited primarily to the third method, namely the use of lightweight aggregates. In recent years a large variety of inorganic lightweight materials have become commercially available. As the potential advantages of lightweight concrete became recognized, the need for reliable technical information as to the suitability of the various materials became apparent. A number of investigations were therefore instituted by various agencies. Perhaps the most widely publicized of these was the recent investigation performed jointly by the Bureau of Reclamation and the National Bureau of Standards under the sponsorship of the Housing and Home Finance Agency. (1) Four classes of material were investigated:

1) Natural lightweight aggregates. This group includes pumice, scoria, volcanic cinders and tuff, etc.

2) Expanded minerals of crystaline structure. This group is comprised of perlite, obsidian, and certain exfoliated micas such as vermiculite. When heated, these minerals explode to form a light fluffy material.

3) By-product aggregates such as expanded blast furnace slag, sintered fly ash, coal cinders, breeze and clinker.

4) Expanded argillaceous materials such as clays, shales and slates, burned in a rotary kiln or sintering machine.

Although all the materials tested produced concretes having good thermal insulation properties as compared with normal concrete, with the exception of sintered fly ash, only the expanded argillaceous materials consistently produced concretes of structural quality. Since this paper deals primarily with lightweight aggregates for structural concrete, only the fourth class of materials will be considered in the discussion which follows.

1. Associate Prof. of Civ. Eng., Univ. of Missouri, Columbia, Mo. 


\section{Description of the Product}

These materials, commonly known as "Haydite" are produced by patented processes of burning raw shales or clays of suitable characteristics in rotary kilns or sintering machines at temperatures ranging from 1900 to $2200 \mathrm{~F}$. At these high temperatures, the material becomes viscous, incipient fusion takes place, and the carbon content is oxidized and formed into a gas. As the gas escapes, the material expands, producing a vesicular structure, which is retained upon cooling and solidification. The resultant product is therefore a highly cellular aggregate, each cell being surrounded by a hard vitreous membrane. Haydite aggregate produces a concrete weighing 80 to 100 pounds per cubic foot as compared to 140 to 150 pounds for normal concretes using sand and pebbles or crushed stone aggregate.

\section{Historical Background and Development}

The process of producing expanded shale aggregates was first perfected at Kansas City in 1917 by Stephen J. Hayde. At about the same time, the Emergency Fleet Building Corporation of World War I advanced the idea of constructing reinforced concrete ships, to alleviate the critical steel shortage. The investigation was conducted by $\mathrm{Mr}$. J. R. Wig, a noted marine engineer, who, in his studies, arrived at the conclusion that concrete ships would be economically feasible provided a concrete having a compressive strength of $\mathbf{5 0 0 0}$ psi could be produced at a weight not to exceed 110 pounds per cubic foot. In pursuing his studies of lightweight concrete, Mr. Wig heard of Stephen Hayde's experiments. He immediately arranged for similar experimental work to be conducted by the Bureau of Standards and as a result, the first aggregate of this type was produced in 1918 in a brick plant near Birmingham, Alabama. A sufficient quantity was produced to supply concrete for the 3000-ton Atlantus, launched in December, 1918. The success of this ship led to the design of larger vessels. Meanwhile, it was found that a more uniform product could be produced by the rotary kiln method. The first aggregate by the new process was produced at the Hannibal, Missouri, plant of the Atlas Cement Company and shipped to shipyards at Jacksonville, Florida, and Mobile, Alabama.

The first vessel constructed with this material was the 7500-ton tanker Selma, launched in June, 1919. The fascinating history of this ship has been reported in detail elsewhere.(2) After three years of satisfactory service, the Selma was struck by a tug, producing a large crack in her hull near the bow. For various reasons, repair was not economically feasible at the time, she was therefore stripped of all her equipment, towed out into Galveston Bay and sunk. In July, 1953, the hull was inspected and samples of the concrete were taken. The concrete was found to be in excellent condition and dry at a depth of $1 / 4$ inch from the surface, indicating negligible absorption. Although there was only $5 / 8$ inches of concrete cover over the reinforcing steel in many places, the steel was found to be in excellent condition. Compressive strength tests were made on 2-inch cubes cut from the hull and interior ribs. Compressive strength values ranged from 8,125 psi to 13,181 for these tests.

During the period between World War I and World War II progress in the development and use of Haydite was very slow. The principal reason for this lack of progress was undoubtedly an economic one. Occasionally a designer would be faced with a problem requiring lightweight structural concrete regardless of cost. Such jobs would generally cost two or three times as much in place as conventional concrete. Some applications were made - one of the 
more notable ones being the construction of the upper deck of the San Francisco - Oakland Bay Bridge. This deck consists of a combination slab of 5-3/8" lightweight concrete topped with a half inch of hard rock mortar. This slab has been in service sixteen years with no sign of failure.(3)

During World War II history repeated itself. Steel was again critical. Recalling the experience of the first war, a number of concrete ships were again built using lightweight aggregates. Some two dozen ships of this type were constructed in the San Francisco area alone. Specifications were extremely rigid, requiring that all test cylinders of each pour should exceed $5000 \mathrm{psi}$ in 28 days. These specifications were successfully met by concrete produced with expanded shale aggregate. $(3)(4)$

In the years following World War II, a number of new aggregate plants were placed in operation. At first their output was used primarily for the manufacture of lightweight concrete blocks and for precast floor and roof panels. As more experience was gained, the material was used for a few monolithic floor and roof jobs - generally as fill material over steel decking. Only since about 1950 have the potentialities of this material for structural concrete become widely recognized and economically attainable. Especially with the development and increased use of flat plate type construction has the use of lightweight structural concrete proved to be competitive. The rapid increase in productive capacity in the Southwest as shown in Fig. 1 is symptomatic of the growth of the industry in the post-war years.

\section{Properties of the Aggregate}

Generally, after burning, the aggregate is ground, screened and graded into commercial sizes. The individual particles are extremely angular, from the $3 / 4$-inch size, which is the usual maximum size commercially available, right down to the minus 100 mesh size. This angularity causes the principal difficulty in the design of workable mixes using this material. Proper gradation of the aggregate is extremely important and for the fines, much smaller grading tolerances are generally specified as compared with normal fine aggregates. To improve workability, some producers recommend a gradation of fines with about twice as much minus fifty-mesh material as is required in concretes using silica sand.(5) Typical grading limits for two types of Haydite aggregate are shown in Fig. 2 as compared with the permissible limits for fine aggregate in accordance with specification ASTM C 33-49.

Fine blending sands have also been used successfully to improve workability. The use of an air-entraining admixture is desirable for the purpose of internal lubrication, rather than for durability. The unit weights of these aggregates vary somewhat depending upon the nature of the raw material used in production. (1)(6) Typical unit weight of expanded shales and slates are 55 pounds per cubic foot for coarse and 70 pounds for fine aggregate. Unit weights for expanded clays are more variable, ranging from 35 to 50 pounds per cubic foot for coarse and 40 to 60 pounds for fine aggregate. Due to the light weight and the large percentage of fines smaller than 100 mesh, these aggregates tend to dust and segregate badly. Many producers market a blended mix, designed primarily for concrete block production. To insure consistent results, separated aggregates are preferred for structural concrete.

Next to density, the most significant property of these aggregates is their high absorption value. Absorption values range from about 7 percent by weight for the expanded shales to as high as 30 percent for some of the expanded clays. Not only does the absorption vary with the type of aggregate and with time, but 
also with the initial moisture content. Fig. 3 shows the results of a series of absorption tests recently conducted by the Missouri State Highway Department. The material tested was an expanded shale blended aggregate.

Whereas absorption is a minor factor with natural heavy aggregates it is extremely important in dealing with these lightweight aggregates. It has been found that the water-cement ratio law applies equally well to Haydite concrete as to natural aggregate concrete. It must be remembered, however, that the water-cement ratio is determined by the effective mixing water, rather than the total water which includes the water absorbed by the aggregate. Furthermore, the critical absorption is not necessarily the total absorption, but rather the absorption which takes place prior to the initial set of the cement gel. To obtain job mixes of uniform consistency, it is therefore imperative that the initial moisture content of the aggregate be maintained at a uniform level.

Haydite type aggregates are surprisingly sound and durable. The results of sodium sulfate tests indicate that the material is equal to gravel and better than most limestones. Resistance to freezing and thawing of structural grade lightweight concretes, has been found to be equal to or better than dense aggregate concretes with or without entrained air. (1)(7)

\section{Physical Properties of Lightweight Structural Concrete}

The density of Haydite concretes varies with the type of aggregate and with the cement factor. Weights for fresh concrete range from about 75 pounds per cubic foot for some of the expanded clays to 110 pounds per cubic foot for expanded shales. Oven dry weights will normally run about ten percent less. Tests conducted by Richart and Jensen $(8)$ indicated that for properly designed mixes, Haydite concretes develop approximately the same strength as natural aggregate concretes for the same water-cement ratio and cement factor. These results have been confirmed by numerous other investigators, and are to be expected, since the crushing strength of the cement paste is the limiting factor.

The relationships between bond, shear, and diagonal tension, and the compressive strength of Haydite concretes are essentially the same as for dense concrete, and the same allowable working stresses have been recommended by the Joint Committee. It has been observed, however, that the ratios between bond, shear, and diagonal tension, and the compressive strength are not constant, but are proportionally lower for strong concretes than for weak ones. This result is in agreement with tests reported by other investigators, (8) and hence for high strength concretes somewhat lower working bond and shear stresses than recommended by the Joint Committee would appear justified.

Perhaps the most controversial property of lightweight concretes is the elastic modulus. A series of experiments have recently been conducted at the University of Toledo under the sponsorship of the Expanded Shale Institute. Unfortunately, results of these tests have not yet been published. Reported values of elastic modulus range from as low as 50 to more than 80 percent of equivalent natural aggregate concrete. Although modulus is primarily a function of the strength, the density of the aggregate also is a factor. Generally, the reported values of $E$ for expanded shale concretes are considerably higher than those for expanded clays. As is the case for natural aggregate concretes, the ratio $\mathrm{E} / \mathrm{fc}$ is not a constant but decreases with increasing compressive strength. Although the absolute value of the modulus is not too critical a factor in reinforced concrete design, the reduced modulus is of considerable concern in prestressed concrete. Additional information on this property is needed and 
the relationship of modulus to density, cement factor, and curing conditions should be better established.

The drying shrinkage of lightweight structural concrete, both with and without air entraining, is generally slightly higher than that of comparable sand and gravel concrete, but due to the lower modulus little or no trouble has been experienced. The total time required for air-dried concretes to come into equilibrium with the humidity of the air is about the same as for sand and gravel concrete, however, the rate of moisture loss is more uniform for Haydite concretes. Whereas heavy concretes will reach 90 percent equilibrium in about 30 days, Haydite concretes require 60 to 70 days to reach the corresponding degree of equilibrium. This phenomenon may be attributed to the high absorption and low capillary potential of the aggregate.

Very little information has been published on creep or plastic flow properties of lightweight concretes. It is known, however, that creep is related to modulus and shrinkage. Exploratory experiments on an expanded clay aggregate indicated an ultimate plasticity factor of about 4.5 as compared to 3.6 for sand-gravel concrete. (Plasticity factor is defined as the ratio of the deflection under sustained load at any time " $\mathrm{t}$ " to the initial elastic deflection). In addition, the initial rate of creep was found to be somewhat greater; this result is not too surprising, since the porous nature of the aggregate permits freer flow of absorbed water from the cement gel. (9) An experimental program to study plastic flow at Kansas State College has recently been initiated under the sponsorship of the Expanded Shale Institute.

Durability of structural lightweight concretes are surprisingly good. Resistance to freezing and thawing has been shown to be equal to or better than dense aggregate concretes. Although these aggregates are very absorptive, their vesicular nature tends to reduce the capillary potential, and with normal to high cement factors, lightweight aggregate concretes are highly impermeable. Lightweight aggregate concrete surfaces exhibit good wearing qualities. In 1945 the City of Tacoma replaced a plank and asphalt floor on the 11th Street bridge with a lightweight concrete deck. This bridge is located on one of the most heavily traveled arterials in the Northwest, carrying an average daily traffic of 35,000 to 40,000 vehicles. Despite this heavy duty, inspection after eight years of service showed no damage except for a small isolated section damaged by excessive rain at the time of construction. Even the finishers' brush marks left during paving operations were found to be intact. (4)

Although the thermal conductivity of the Haydite concretes is greater than that of other lightweight aggregate concretes, it is considerably less than the conductivity of dense concretes. Reported k-values (B.t.u. per hr., sq. ft., oF, 1 in. thickness) range from 2 for the lighter expanded clays to 4 for the denser expanded shales as compared to values of 6 to 9 for dense concrete. All data reported indicate the existence of a definite correlation between density and thermal conductivity. (1)

\section{Effect of Physical Properties on Design}

On the basis of presently accepted design methods there are two sources of economy to be derived from the use of lightweight reinforced concrete. The first source is of course the reduced dead load, resulting in higher structural efficiency, that is a higher ratio of useful live load to dead load capacity. The second source of economy results from the lower elastic modulus of Haydite concrete. Due to the lower modulus and the corresponding increase in the modular ratio, the section design coefficient $K$ is greater, and hence for 
balanced design of rectangular beams and flat slabs, the effective depth is reduced. This result is summarized in Table 1 for three assumed ratios of $\mathrm{E}_{\mathrm{L}} / \mathrm{E}_{\mathrm{H}}$ : where,

$\mathrm{E}_{\mathrm{L}}=$ modulus of elasticity of lightweight concrete

$\mathrm{E}_{\mathrm{H}}=$ modulus of elasticity of heavy concrete.

The permissible reduction in depth shown in Table 1 is on the basis of equal total load. The reduced dead load, when lightweight concrete is used, would further reduce the required depth. It should be noted however that the decrease in depth is offset by an increase in the total area of steel required.

The effect of increased modular ratio results in a lowering of the neutral axis, i.e. in a marked increase in $k_{d}$, the compression zone, and a slight decrease in the internal moment arm, jd. As a result the steel percentage required for balanced reinforcement is increased. These results are clearly demonstrated in the design chart shown in Fig. 4.

Similarly, on the basis of elastic theory, the efficiency of the compressive steel is increased for doubly reinforced beams as a result of the larger values of $n$ and $k$. However, due to the effect of plastic flow, these factors have little effect on the ultimate capacity of the section. The apparent increase in efficiency is therefore misleading. In any case, it must be kept in mind that balanced design is not necessarily the most economical design. Economical design is a function of the relative cost of steel, concrete, formwork and labor, factors which are extremely variable and can only be determined with any degree of accuracy by comparative bids.

The design advantage resulting from decreased modulus does not apply to T-beams; for these members the internal moment arm is determined primarily by the flange thickness. Similarly, no advantage other than a reduction in dead load is to be gained for axially loaded columns, since present design formulae do not depend on the modular ratio. For members in which deflection is critical, the lower modulus of elasticity is a disadvantage. Such members must be deepened to compensate for reduced modulus by an increase in the moment of inertia.

In prestressed concrete design, the decreased modulus of elasticity and the increase in the related plasticity factor is a distinct disadvantage. The theoretical ultimate loss of prestress due to combined shrinkage, and elastic and plastic deformation can amount to as much as 50,000 or $60,000 \mathrm{psi}$. When lightweight aggregate concrete is used the practice of assigning an arbitrary percentage for prestress loss should be used with caution, for, although shrinkage is a fairly constant factor for a given set of conditions, the prestress loss due to elastic compression and creep will vary with the magnitude of the working stress level in the concrete. The use of Haydite concrete for prestressing may offer some advantage as far as fire protection is concerned, due to its lower k-value. Very little information is available on the fire resistance of prestressed concrete, but a number of tests are reported to be in progress at the present time.

\section{Lightweight Concrete Mix Design and Control}

One of the difficulties arising in the use of lightweight concretes is the fact that better job mix control is required to obtain the strengths and consistencies readily obtained in the laboratory. The more precise control required has been reflected in higher unit cost - a cost far in excess of that justified by the higher aggregate cost. Another factor affecting mix economy is the fact that 
due to the higher percentage of fines somewhat higher cement factors may be required. It has been repeatedly demonstrated, however, that by the use of air entraining and with proper grading, plastic mixes can be produced with normal cement factors.

The most noticeable difference in first working with these aggregates is the difference in appearance and handling. Dry appearing batches work well, and when vibrated, water tends to rise to the surface. The relationship between slump consistency and workability for lightweight mixes is markedly different than for heavy concretes. Due to the angularity and harshness of the aggregate, slump cone readings of plastic lightweight mixes will consistently be lower than those for dense aggregate mixes of the same workability. It is recommended that slumps of 1-1/2 to 2 inches less than those normally used with heavy concrete be specified when light weight aggregates are used.

Proper grading is extremely important in effecting design economy. Good grading is hard to obtain due to segregation in the aggregate stock piles. Separated aggregates, and prewetting of the aggregate is helpful in correcting this problem. Entrained air is extremely useful in correcting large grading deficiencies. Due to the large percentage of fines, larger quantities of air can be entrained in lightweight mixes without seriously reducing compressive strength. Accurate measurement of entrained air is difficult. The pressure type air meter can not be used and the gravimetric method is not too satisfactory because the determination of the theoretical unit weight of the aggregate is difficult. Admixtures such as plastiment and pozzolith which tend to disperse the cement may be useful. These admixtures produce a more uniform $\mathrm{mix}$ and also reduce the water content required for a given slump consistency.

prewetting of the aggregate is a well accepted practice and is desirable for the following reasons:

1) Segregation of the aggregate is reduced or eliminated.

2) Tendency to dust is reduced thus preventing loss of valuable fines.

3) Absorption is more uniform and predictable.

4) Mixing time can be reduced somewhat.

Some reports indicate that mixing with dry aggregate produces a somewhat stronger concrete. Tests made for the shipbuilding program showed a 7 percent increase in favor for the dry aggregate, along with a 3 percent decrease in weight and an increase in freezing and thawing resistance. (7) This result may be explained by the continued absorption of the aggregate between mixing time and time of set, resulting in an effective reduction of the water-cement ratio.

\section{Mixing and Mix Control Problems}

Since the total water required may vary widely depending on the amount of absorption, the control of mixing water presents a serious difficulty. For plastic mixes satisfactory control has been achieved by the slump cone test. This test is more sensitive for Haydite concretes than for dense concretes. Since consistency is a measure of the unabsorbed water, the effective mixing water and hence the water-cement ratio can be controlled in this manner.

The mixing cycle is considerably different from that used for dense concretes and the total time required is somewhat longer. On a recent bridge job in the State of Missouri the aggregates, part of the air entraining agent, and part of the water were premixed for about one minute, following which the cement and the remaining air and water were added and mixed for an additional 
four or five minutes. Considerable difficulty was experienced due to nonuniform air content and caking of the mixer blades. It was found that better results could be obtained by diluting the air entraining agent (neutralized Vinsol resin) 3:1 with water. Caking was found to be more severe with some types of mixers and with the lower slump consistencies. The caking tendency was corrected by using a paddle type mixer and by introducing a shot of water into the mixer to wash the drum clean prior to adding the Haydite. The following mixing cycle is recommended by Haydite producers in the Texas area:(5)

15-20 seconds mixing water and Vincol resin only in the drum, followed by 30-40 seconds with aggregate added and then followed by one minute after the cement is put in. The total required mix time is therefore approximately two minutes.

This procedure permits uniform dispersal of the Vinsol resin. For ready-mix and transit-mix the usual agitating speeds of 2-6 rpm are insufficient to keep the mix homogenous. The drum should be turned at high speed for a minimum of 30 seconds prior to unloading to prevent separation of the mortar from the coarse aggregate during discharge.

\section{Placing and Finishing}

It has already been pointed out that slump consistencies for the lightweight concrete mixes are not directly comparable with those for dense concrete. Lower slumps are also desirable to prevent segregation. Entrained air is useful in preventing segregation by increasing the stickiness of the mix, but excessive entrained air is undesirable because it produces blow holes and pock marks on the surface of the concrete. Over-vibration should be avoided for it produces segregation and causes the lighter weight coarse aggregates to rise to the surface making finishing difficult. Most placing and finishing difficulties experienced are due to variation of absorbed water producing alternately dry and wet batches. This difficulty is best overcome by using consistency control. Aluminum floats have been found most successful for finishing, followed by the use of a soft, bristled push broom.

\section{Economic Considerations}

The question which confronts the designer and which is perhaps the most difficult to answer is: "Under what circumstances can lightweight concrete be used economically?" Economic use can be separated into three groups. In the first group are those structures where dead load reduction is imperative, and lightweight concrete can be specified regardless of cost. An example of such application was found in the reconstruction of the Tacoma Narrows bridge. The use of a lightweight concrete made possible the construction of a four lane bridge re-using the piers which had been originally designed for a two lane structure. In other cases the use of lightweight concrete has made it possible to construct additional floors on buildings without overloading existing footings. The second class of structures for which a clear cut decision can be made are those structures in which density is desired. Such structures would include gravity dams and radiation shields in atomic energy plants. It is in the intermediate class, or third group, that decision may be difficult, and in the final analysis, economy can only be determined by alternate bids.

The following factors favor the use of lightweight concrete and should be kept in mind by the designer: 
a) Reduction in dead load permitting shallower sections, and smaller columns and footings.

b) Reduction of seismic loads.

c) Construction economies which can be effected by using lighter forms, and reduction of concrete handling cost.

d) The reduced modulus of elasticity permits larger deflection and hence lightweight concrete is more shock resistant. On the other hand, the reduced modulus is a disadvantage in prestressed concrete application, or where rigidity is desired.

e) Increased insulating value. This factor in itself may justify any additional cost.

These advantages are offset by the increased aggregate cost and by increased costs due to mixing and handling. The latter will vary regionally, and in localities where contractors have become experienced in lightweight concreting techniques, lightweight concrete can be specified at no penalty other than the higher aggregate cost.

For precast concrete structural products the use of lightweight concrete is a natural. Not only are shipping and handling costs materially reduced, but under factory control conditions the mixing, placing and finishing of lightweight concrete present no particular difficulties.

The versatility of lightweight aggregate concrete is truly amazing. In this material are combined great strength with relatively light weight, resilience and toughness, good durability against weathering and chemical action, imperviousness to moisture, and excellent insulation and fire resistance, all at relatively low cost. There is little doubt that when architects and engineers become more familiar with the potentialities of this material its use will become the rule rather than the exception in building and bridge construction.

\section{ACKNOWLEDGEMENTS}

The author wishes to thank Mr. Cedric Willson, Vice President, Texas Industries, Inc. and chairman of the Technical Problems Committee of the Expanded Shale Institute, and Mr. R. A. Currie of the Missouri State Highway Department for their helpful cooperation in collecting data presented in this paper.

\section{REFERENCES}

1. "Lightweight Aggregate Concretes", Bulletin, Housing and Home Finance Agency, August 1949.

2. Willson, Cedric, “The Report of an Investigation on the Condition and Physical Properties of Expanded Shale Reinforced Concrete After 34 Years Exposure to Sea Water", Report, Expanded Shale Institute, 1954.

3. Andrew, Charles E., "Use of Expanded Shale Concrete in Bridge and Ship Construction", Expanded Shale Concrete Facts, Vol. 1, No. 1, 1954.

4. Andrew, Charles E., "Structural Uses of Expanded Shale Concrete", Expanded Shale Concrete Facts, Vol. 1, No. 2, 1954.

5. Murlin, John A, and Willson, Cedric, "Field Practice in Lightweight Concrete ${ }^{\circledast}$ ACI Journal, May 1949, Proc. Vol. 45, pp. 21-36. 
6. Kluge, Ralph W., Sparks, Morris M. and Tuma, Edward C., "LightweightAggregate Concrete", ACI Journal, May 1949, Proc. Vol. 45, pp. 625-642.

7. Price, Walter H. and Cordon, William A., "Tests of Lightweight-Aggregate Concrete Designed for Monolithic Construction", ACI Journal, April 1949, Proc. Vol. 45, pp. 581-599.

8. Richart, Frank E. and Jensen, Vernon P., “Tests of Plain and Reinforced Concrete Made with Haydite Aggregates”, Bulletin No. 237, University of Illinois Engineering Experiment Station.

9. Pauw, A. and Thibodeaux, M. H., “The Use of Prestressing Techniques in Controlling Plastic Flow Deflections in Beams and Slabs", Paper presented at ACI Regional Convention, Houston, Texas, October 1953. 


\begin{tabular}{|l|ll|l|l|l|}
\hline \multicolumn{1}{|l|}{ Elastic Modulus, } & $\frac{E_{L}}{E_{H}}$ & 0.50 & 0.67 & 0.75 \\
\hline Modular Ratio, & $\frac{n_{L}}{n_{H}}$ & 2.00 & 1.50 & 1.33 \\
\hline Section Design Coefficient, $\frac{K_{L}}{K_{H}}$ & 1.33 & 1.20 & 1.14 \\
\hline Effective Depth, & $\frac{d_{L}}{d_{H}}$ & 0.87 & 0.91 & 0.94 \\
\hline Steel Percentage, & $\frac{P_{L}}{P_{H}}$ & 1.43 & 1.25 & 1.17 \\
\hline Steel Area, & $\frac{A_{S L}}{A s H}$ & 1.24 & 1.14 & 1.10 \\
\hline
\end{tabular}

tABLE I. RELATIVE DESIGN FACTORS for Balanced Design of Lightweight and Heavy Reinforced Concrete Beams 


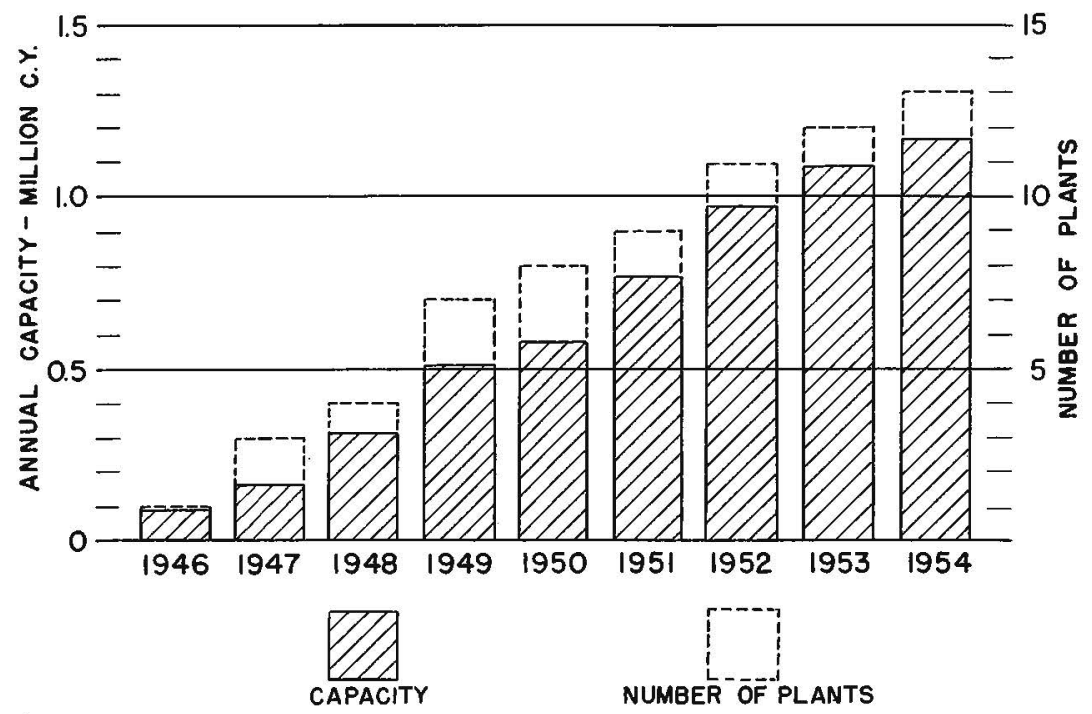

FIG. I ANNUAL CAPACITY OF HAYDITE PRODUCTION IN THE SOUTHWEST (Kansas, Missouri, Oklahoma, Arkansas, Loussiana and Texas)

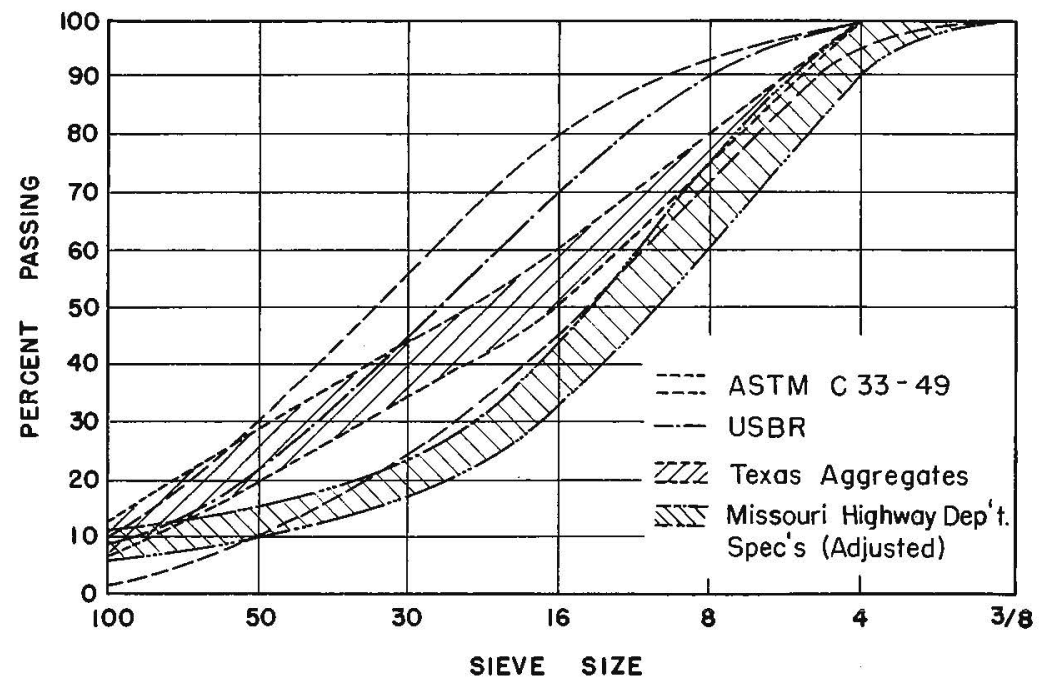

FIG. 2 FINE AGGREGATE GRADING LIMITS 


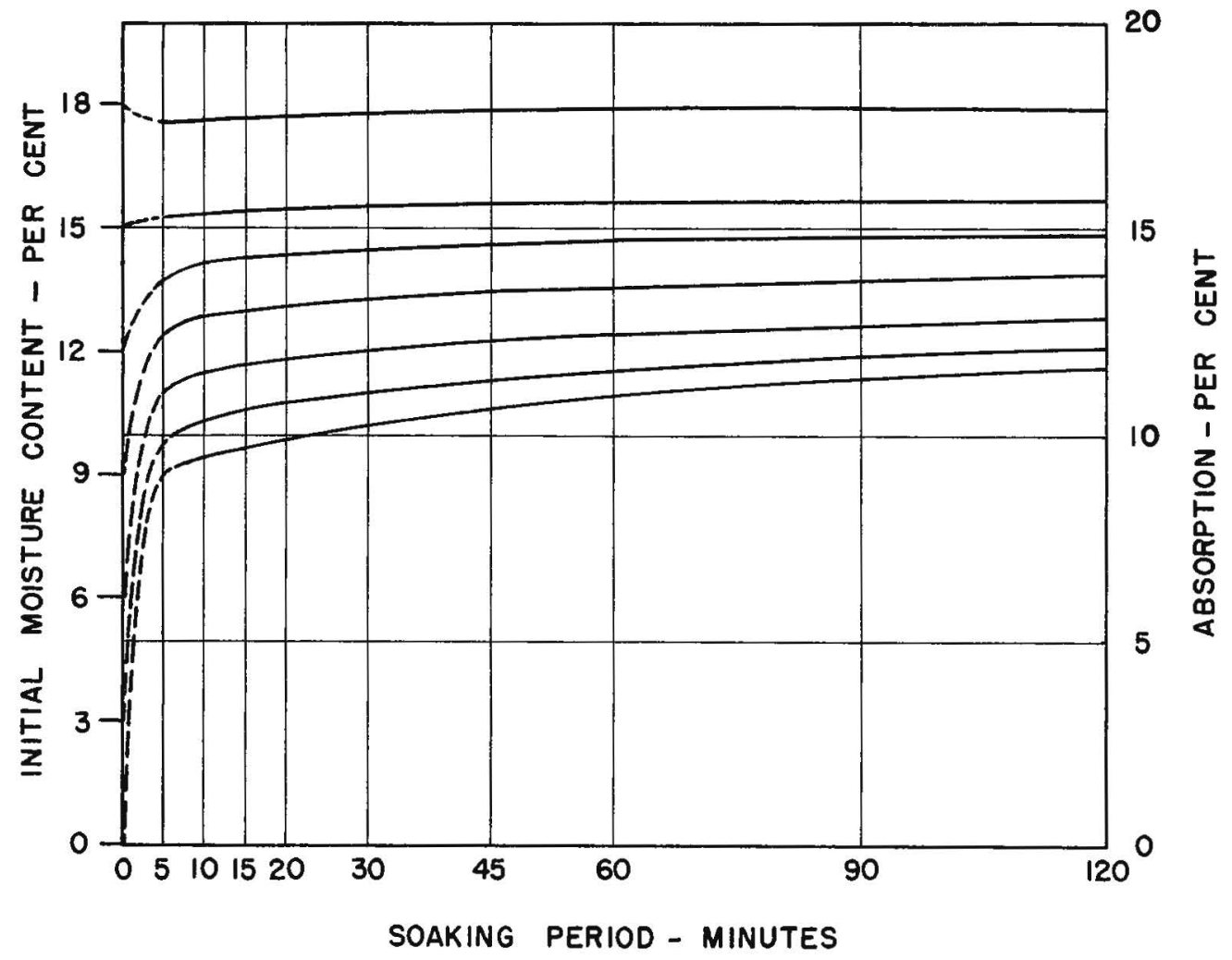

FIG. 3 TYPICAL ABSORPTION CURVES FOR AN EXPANDED SHALE BLENDED AGGREGATE 


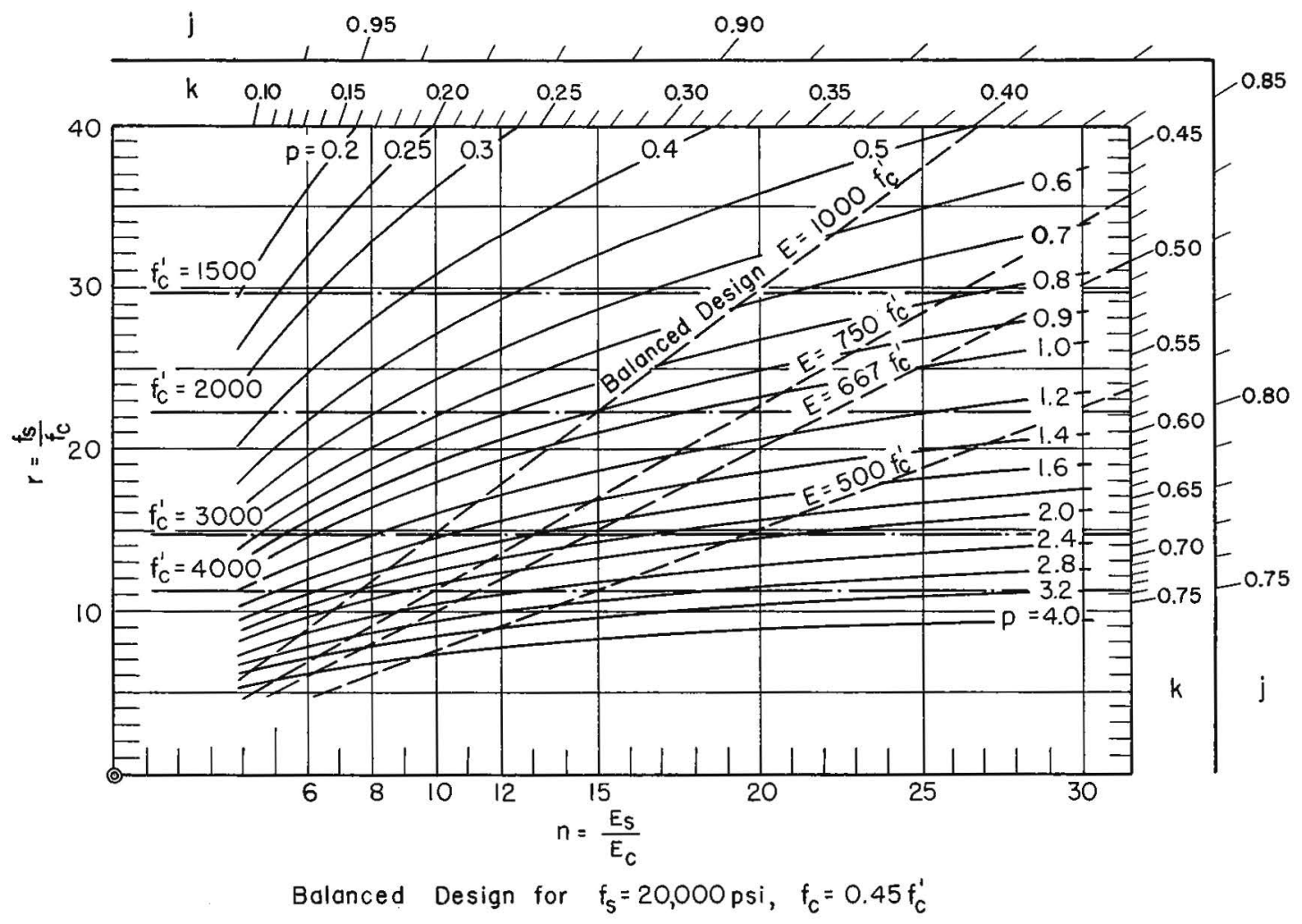

FIG. 4 DESIGN CHART FOR RECTANGULAR BEAMS 


\section{PUBLICATIONS OF THE ENGINEERING REPRINT SERIES}

Reprint

No.

*1. Response of Circuits to Steady-State Pulses, by D. L. Waidelich, Professor of Electrical Engineering. Reprinted from the Proceedings of the I.R.E., Vol. 37, p. 1396, December 1949.

*2. Heat Transfer to Water Boiling Under Pressure, by E. A. Farber, Assistant Professor of Mechanical Engineering, University of Wisconsin, and R. L. Scorah, Professor of Mechanical Engineering. Reprinted from the Transactions of the A.S.M.E., Vol. 70, p. 369, May 1948

*3. Steady-State Waves on Transmission Lines, by D. L. Waidelich, Professor of Electrical Engineering. Reprinted from the Transactions of the A.I.E.E., Vol. 69, p. 1521, 1950.

4. Theory of the Adiabatic Bubble, by Ralph Scorah, Professor of Mechanical Engineering. Reprinted from the Proceedings of the Midwestern Conference on Fluid Dynamics, J. W. Edwards, Ann Arbor, Michigan, 1951.

5. Equivalent Load Method for Analyzing Prestressed Concrete Structures by Robert B. B. Moorman Professor of Civil Engineering. Reprinted from the Journal of the American Concrete Institute, Vol. 23, p. 405 , January 1952 .

*6. Design of Low Frequency Constant Time Delay Lines, by C. M. Wallis, Professor of Electrical Engineering. Reprinted from Transactions of the A.I.E.E., Vol.71, Part 1, p. 135, April 1952.

*7. The Engineer Becomes a Professional Manager, by Harry Rubey, Professor of Civil Engineering. Reprinted from the Journal of Engineering Education, Vol. 43, p. 338, January 1953.

8. Use of the Centrifugal Governor Mechanism as a Torsional Vibration Absorber, by O. A. Pringle, Assistant Professor of Mechanical Engineering. Reprinted from the Transactions of the A.S.M.E. Vol. 75, p. 59 , January 1953

*9. How to Plan for the Safe and Adequate Highways We Need, by Harry Rubey, Professor and Chairman of Civil Engineering. Reprinted from the General Motors “Better Highways Awards”, 1953.

*10. A Dynamic Analogy of Foundation - Soil Systems, by Adrian Pauw, Associate Professor of Civil Engineering. Reprinted from Symposium on Dynamic Testing of Soils, Special Technical Publication No. 156, American Society for Testing Materials, 1953.

11. Ternary System Ethyl Alcohol--n--Heptane-Water at $30^{\circ} \mathrm{C}$, by Joseph L. Schweppe, Research Engineer, C. F. Braun and Co. and James R. Lorah, Associate Professor Chemical Engineering, Reprinted from Industrial and Engineering Chemistry, Vol. 26, p. 2391, November 1954.

The Rectifying Property of Polarized Barium Titanate, by Donald L. Waidelich, Associate Director, Engineering Experiment Station and Professor of Electrical Engineering. Reprinted from Journal of the Acoustical Society of America, Vol. 25, p. 796, July 1953.

12. Chip Breakers Studies 1, Design and Performance of Ground Chip Breakers, Erik K. Henriksen, Associate Professor of Mechanical Engineering

Balanced Design Will Fit the Chip Breaker to the Job, from American Machinist, April 26, 1954, pp. 117-124, Special Report No. 360

How to Select Chip Breakers I, II, III, from American Machinist, May 10, 1954, pp. 179, 181, 183, Reference Book Sheets

Chip Breaking-A Study of Three-Dimensional Chip Flow, from page No. 53-5-9, presented at the A.S.M.E. Spring Meeting, Columbus, Ohio, April 28-30, 1953

Economical Chip Breakers for Machining Steel, from Technical Aids to Small Business, May 1954, pp. 1-8

13. The Design of Sampled-Data Feedback Systems by Gladwyn V. Lago, Assoclate Professor of Electrical Engineering and John G. Trumal, Polytechnic Institute of Brooklyn. Reprinted from Transactions of the A.I.E.E., Vol. 73, Part 2, p. 247, 1954.

14. Selection of Personnel by George W. Elliott, Assistant Professor of Mechanical Eingineering. Reprinted from the 1954 Transcript of the Midwest Feed Production School.

15. Lightweight Aggregates for Structural Concrete by Adrian Pauw, Associate Professor of Civil Engineering. Reprinted from the Proceedings of the A.S.C.E., Vol. 81, Separate No. 584, January 1955.

Out of Print 

University of Missouri Libraries

University of Missouri

MU Engineering Experiment Station Series

Local Identifier

Pauw1955

Capture information

Date captured

2018 May

Scanner manufacturer Ricoh

Scanner model

MP C4503

Scanning software

Optical resolution

600 dpi

Color settings

File types

Grayscale, 8 bit; Color, 24 bit Tiff

Source information

Format

Content type

Notes
Book

Text

Digitized duplicate copy not retained in collection.

Derivatives - Access copy

Compression

Editing software

Resolution

Color

File types

Notes
LZW

Adobe Photoshop

$600 \mathrm{dpi}$

Grayscale, 8 bit; Color, 24 bit

Tiffs converted to pdf

Greyscale pages cropped and canvassed. Noise removed from background and text darkened. Color pages cropped. 